\title{
Pilot investigation of hypothermia in neonates receiving extracorporeal membrane oxygenation
}

\author{
S Ichiba, H M Killer, R K Firmin, S Kotecha, A D Edwards, D Field
}

Arch Dis Child Fetal Neonatal Ed 2003;88:F128-F133

See end of article for authors' affiliations

Correspondence to: Professor Field, Department of Child Health, Robert Kilpatrick Clinical Sciences Building, University of Leicester, Leicester LE2 7LX, UK;

david.field@uhl-tr.nhs.uk

Accepted 22 July 2002
Background: Infants requiring extracorporeal membrane oxygenation (ECMO) support represent a high risk group in terms of cerebral injury. Mild hypothermia both during and after cerebral hypoxic ischaemia appears to be a promising strategy for offering neuroprotection.

Objective: To investigate whether mild hypothermia was both feasible and safe in infants receiving ECMO as a prelude to any formal assessment of this approach in a randomised trial.

Methods: Twenty infants (body weight less than $5 \mathrm{~kg}$ ) with severe cardiopulmonary insufficiency, referred for ECMO support at Glenfield Hospital, Leicester, were enrolled in this study. Twenty consecutive infants (compromising four groups of five) were studied. Baseline data were obtained from a control group who were run throughout their course at $37^{\circ} \mathrm{C}$. The patients in the next group were managed with a core temperature of $36^{\circ} \mathrm{C}$ for the first 12 hours of their ECMO run, before being warmed up to $37^{\circ} \mathrm{C}$. After successful completion, the next group of five were cared for at $35^{\circ} \mathrm{C}$ for the first 12 hours, and, there having been no previous complications, the final group were cared for at $34^{\circ} \mathrm{C}$ for the first 12 hours. Patients were assessed clinically and biologically. In addition to routine laboratory tests, cytokines (interleukin 6, interleukin 8 , tumour necrosis factor $\alpha$, and $C$ reactive protein) were measured and coagulation tests (D-dimer, thrombin-antithrombin III complex, plasmin- $\alpha_{2}$ antiplasmin complex) were performed serially for five days.

Results: There were no significant differences among the four groups in gestational age, birth weight, age at the time of ECMO, Apgar scores at one and five minutes, $\mathrm{pH}$ before cannulation, oxygenation index, duration of ECMO, and survival rate to discharge from hospital. No adverse effects of mild hypothermia were found on patient management during ECMO. Laboratory data for up to five days of ECMO also showed no difference among the four groups.

Conclusion: Mild hypothermia $\left(34^{\circ} \mathrm{C}\right)$ for the initial 12 hours of an ECMO run is feasible.
$\mathrm{E}$ xtracorporeal membrane oxygenation (ECMO) is an invasive method of life support used in severe respiratory or cardiorespiratory failure. It entered clinical practice as an extension of the technology that produced cardiopulmonary bypass. ${ }^{12}$ In the last 20 years, it has been used to support over 10000 mature infants with severe cardiorespiratory failure. Most recent evidence available indicates that ECMO is currently the most effective form of life support for such infants. ${ }^{2}$ However, outcome data from both randomised trials and clinical series indicate that ECMO eligible infants are at high risk of neurodevelopmental delay, with, on average, about $20-30 \%$ of survivors suffering some form of impairment irrespective of whether they received ECMO or some other less invasive means of life support. ${ }^{2-4}$ For most infants, the precise cause of the neurological damage is uncertain. However, there is no doubt that, for infants who do receive ECMO, maximal physiological derangement from the underlying condition normally coincides with a decision to use ECMO, and also the establishment of ECMO poses a further insult to the cerebral circulation and hence the brain.

Much interest has been focused in recent years on perinatal hypoxic-ischaemic brain injury, which is characterised by biphasic changes in cellular energy metabolism: a largely reversible impairment during the insult and a secondary derangement beginning within 12 hours of the insult, characterised by a decline in cerebral high energy phosphate. ${ }^{5}$ This period between primary and delayed injury offers the potential for therapeutic intervention. Many recent studies have suggested that cooling by $3-4^{\circ} \mathrm{C}$ after experimental hypoxia-ischaemia reduces the severity of brain injury and can be achieved safely in infants who are suffering from acute neonatal encephalopathy. ${ }^{6-11}$ Clinical use of mild hypothermia in adults at risk of neurological impairment has produced mixed results. ${ }^{12}{ }^{13}$ Hypothermia is relatively non-invasive and has been widely used in cardiopulmonary bypass during open heart surgery. It may be a useful neuroprotective treatment for infants undergoing ECMO.

Extracorporeal circulation permits body temperature to be easily and tightly controlled using adjustments to the temperature setting of the heat exchanger, which is an integral part of the circuit. However, induced hypothermia has been associated with a number of complications including arrhythmias and hypotension, tissue hypoperfusion, coagulopathies, pulmonary hypotension, and pulmonary infections. ${ }^{14}$ Most reported complications of hypothermia were associated with deep hypothermia (core temperature $<30^{\circ} \mathrm{C}$ ) during a short period of cardiopulmonary bypass. The maintenance of normothermia represents one of the major differences between conventional cardiopulmonary bypass and conventional ECMO. The most immediate concern about the use of hypothermia during ECMO was the production of secondary clotting abnormalities. Activated clotting time is tightly controlled during ECMO by using heparin to inhibit thrombus formation in the extracorporeal circuit while minimising any bleeding tendency. Interference with the routine system for monitoring heparin dosage (which measures activated clotting time at $37^{\circ} \mathrm{C}$ ) was considered inevitable if hypothermia was used in patients receiving ECMO. There was also

Abbreviations: ECMO, extracorporeal membrane oxygenation; $\mathrm{TNF} \alpha$, tumour necrosis factor $\alpha$; IL, interleukin; ELISA, enzyme linked immunosorbent assay; PAP, plasmin- $\alpha_{2}$-antiplasmin complex; TAT, thrombin-antithrombin III complex 
concern that increased blood viscosity during hypothermia may disrupt the circuit, particularly the oxygenator.

Given the high rate of adverse neurodevelopmental outcomes in infants sick enough to receive ECMO, there was great interest in any technique that could reduce this risk. It was clear that a definitive answer on the value of mild hypothermia would require a randomised trial, but in the first instance it was necessary to show that the approach did not have obvious adverse consequences. The aim of this study was to assess the safety and feasibility of exposing infants receiving ECMO support to core temperatures of less than $37^{\circ} \mathrm{C}$.

\section{PATIENTS AND METHODS}

The study included 20 infants supported with ECMO in the period March 1998 to December 1998 at the Paediatric Intensive Care Unit of Glenfield Hospital. The study was approved by Leicestershire Health Authority ethics committee. Patients receiving ECMO in Leicester come from all over the United Kingdom and occasionally mainland Europe. Such children, by definition, are in extremis, and undue delay in establishing ECMO could not be justified. As a result, it seemed inappropriate to seek consent from parents as soon as they arrived in Leicester anxious and with little or no understanding of ECMO. The work was therefore treated as a modification of our normal clinical protocol; however, we provided all parents with an information sheet about the work and sought assent. As a separate safeguard, we established an independent data monitoring committee who were informed of patients recruited on a case by case basis.

\section{Entry criteria}

All neonates (neonates defined as infants up to 28 days of age) were eligible for recruitment to the study if they met the unit's standard criteria for initiating ECMO:

- near term babies with body weight between 2 and $5 \mathrm{~kg}$, suffering from severe but potentially reversible respiratory failure (defined as oxygen index about 40, or arterial partial pressure of carbon dioxide $\left(\mathrm{PaCO}_{2}\right)$ greater than $12 \mathrm{kPa}$ for at least three hours);

- less than 10 days of high pressure ventilation;

- no contraindication for ECMO support-for example, ventricular haemorrhage extending beyond the subependymal or choroidal region, presence of a major congenital or chromosomal anomaly, or severe encephalopathy.

It is important to note some infants became unwell for the first time at several days of age. Apart from the period of hypothermia management of the ECMO circuit, followed the standard policy. ${ }^{15}$

\section{ECMO cannulation}

As soon as infants arrived at the ECMO unit, they were assessed by the consultant cardiothoracic surgeon in charge of ECMO. Either venoarterial or venovenous bypass was selected according to the infant's needs. Patients were cannulated through the right internal jugular vein for drainage and the right common carotid artery for return in venoarterial bypass, and the right internal jugular vein was cannulated with a double lumen cannula (12 or 15 Fr; Jostra7, Herringen, Germany) for venovenous bypass. In the case of venoarterial bypass, both vessels were ligated peripherally, and in the case of venovenous bypass, the semi-Seldinger technique was used for cannulation to allow patency of the right internal jugular vein. Before cannulation, 50-100 units/kg heparin was given intravenously to the patient.

\section{ECMO circuit}

A standard ECMO circuit was used consisting of $1 / 4$ inch poly(vinyl chloride) Tygon S-65-HL tubing (Norton Performance Plastics, Acton, Ohio, USA), $0.8 \mathrm{~m}^{2}$ spiral wound silicone membrane oxygenator (model 0800), with inline countercurrent heat exchanger and collapsible assist reservoir (Avecor Cardiovascular, Plymouth, Minnesota, USA). A roller pump (Stockert; Sorin Biomedical, Saluggia, Italy) with Seabrook bladder box servocontroller was used. The circuit was flushed with carbon dioxide and then filled with about 500 ml Ringer's lactate solution and albumin. This clear prime was then displaced by 1 unit of citrated packed red cells to which calcium and heparin had been added. The $\mathrm{pH}$ was adjusted with sodium bicarbonate before use.

\section{Management of ECMO}

The ECMO circuit was managed for 24 hours a day by a team of intensive care nurses specially trained in ECMO and capable of performing surveillance and emergency repairs to the circuit. As soon as the patients were stabilised on ECMO, ventilator settings were reduced gradually to "rest settings" - that is, peak inspiratory pressure of $20 \mathrm{~cm} \mathrm{H}_{2} \mathrm{O}$, positive end expiratory pressure of $10 \mathrm{~cm} \mathrm{H}_{2} \mathrm{O}$, low rate ( 10 breaths/min), and low $\mathrm{FIO}_{2}$ of $30 \%$. Patients were sedated with morphine and midazolam but not paralysed. Activated clotting time was monitored hourly (at $37^{\circ} \mathrm{C}$ ) using Hemochron 401 (International Technidyne Inc, Edison, New Jersey. USA) and maintained between 160 and 200 seconds by adjusting heparin dosage during ECMO. Blood flow rate and sweep gas flow through the oxygenator was adjusted to keep $\mathrm{PaO}_{2}$ at 6-8 kPa or $\mathrm{SaO}_{2}$ (oxygen saturation in arterial blood) at $>85 \%$ and $\mathrm{PaCO}_{2}$ at 4-6 kPa in venovenous bypass, $\mathrm{PvO}_{2}$ (partial pressure of oxygen in venous blood) at 4-6 kPa or $\mathrm{SvO}_{2}$ (oxygen saturation in venous blood) at $>65 \%$ and $\mathrm{PvCO}_{2}$ (partial pressure of carbon dioxide in venous blood) at $6-8 \mathrm{kPa}$ in venoarterial bypass. Oxygenator function was checked by measuring blood gases before and after application of the oxygenator. Haemoglobin concentrations were kept above 140 g/l to maximise the oxygen carrying capacity, and platelet counts were kept above $100000 / \mathrm{mm}^{3}$ by transfusion. Prothrombin time, activated partial thromboplastin time, and fibrinogen levels were monitored and corrected by giving fresh frozen plasma and cryoprecipitate. Albumin levels were kept above $35 \mathrm{~g} / \mathrm{l}$ by administering human albumin solution. They were weaned from ECMO and decannulated when chest radiograph appearance and lung compliance had improved, and adequate gas exchange without excessive ventilation (peak pressure $<30 \mathrm{~cm} \mathrm{H} \mathrm{H}_{2} \mathrm{O}, \mathrm{FIO}_{2}<60 \%$ ) could be shown during a "trial off" ECMO.

\section{Study groups}

The study population compromised the following infants: group 1, five neonates maintained at $37^{\circ} \mathrm{C}$ throughout their ECMO course (control); group 2, five neonates maintained at $36^{\circ} \mathrm{C}$ for the first 12 hours of their ECMO run; group 3, five neonates maintained at $35^{\circ} \mathrm{C}$ for the first 12 hours of their ECMO run; group 4, five neonates maintained at $34^{\circ} \mathrm{C}$ for the first 12 hours of their ECMO run. The next reduction in temperature only occurred after the successful completion of the previous stage with no adverse effects noted.

Rectal temperature was monitored with a temperature probe and was taken to represent the baby's core temperature. The core temperature, arterial blood pressure, electrocardiogram, respiratory rate, and pulse oximetry were shown continuously on the monitor screen (Hewlett-Packard HP Component Monitoring System model 66S). Mean arterial blood pressures recorded were calculated from the following formula: mean arterial blood pressure $=(($ systolic - diastolic pressure)/3) + diastolic pressure. As soon as ECMO was established, the temperature setting of the ECMO water bath (Cincinnati Sub-Zero heater, Cincinnati, Ohio, USA) and radiant warmer was adjusted to achieve the core temperature determined by the protocol. After 12 hours of hypothermia, the infants were warmed up to $37^{\circ} \mathrm{C}$. 


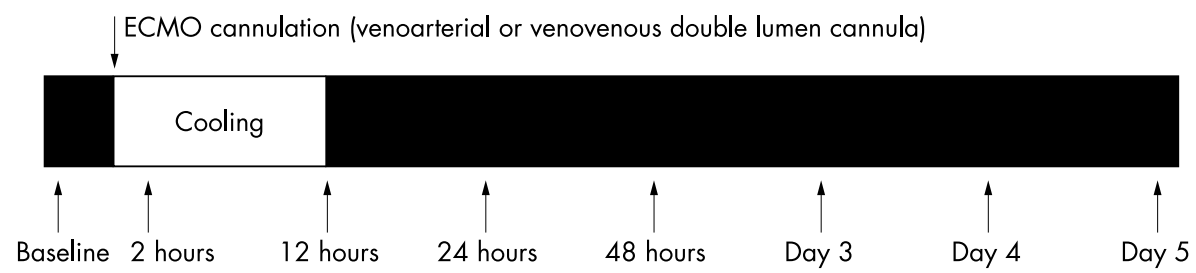

Figure 1 Blood sampling schedule adopted for each patient receiving extracorporeal membrane oxygenation (ECMO).

\section{Collection of blood samples}

Initial blood samples were drawn from the arterial line as soon as the patient arrived at our institution-that is, before cannulation. After the initiation of ECMO, blood samples were drawn from the blood sampling port attached to the ECMO circuit. Blood samples for arterial blood gases were drawn from the arterial line. Blood samples were drawn before cannulation $(\mathrm{t}=0)$ and 2, 12, 24, and 48 hours after the start of ECMO, and then on day 3, 4, and 5 (day 0 was defined as the day when the patient was cannulated for ECMO (fig 1). Routine blood tests included: arterial or venous blood gases; full blood count including white cell and platelet numbers; electrolytes and calcium; coagulation screen-that is, prothrombin time and activated partial thromboplastin time expressed as the international normalised ratio-fibrinogen levels, and D-dimer; urea and creatinine; liver function tests including activities of alanine aminotransferase, aspartate aminotransferase, alkaline phosphatase, and lactate dehydrogenase. Clotting studies were all performed at $37^{\circ} \mathrm{C}$. We were aware that functional measurements of clotting should have been made at the patient's body temperature but could identify no validated methodology to carry this out in a clinical setting. Similarly all blood gases were measured at $37^{\circ} \mathrm{C}$ because we felt that, in the intensive care setting, with such dependent infants, it was unlikely that we could ensure that temperature correction was performed consistently by the clinical staff.

Blood samples for assays not available in the routine laboratory were centrifuged at $2000 \mathrm{~g}$ for 15 minutes at $4^{\circ} \mathrm{C}$ within 20 minutes of collection and stored at $-70^{\circ} \mathrm{C}$ until further analysis. D-Dimer (Nycomed, Birmingham, UK), thrombin-antithrombin III complex (TAT) (Dade Behring, Milton Keynes, Bedfordshire, UK) and plasmin- $\alpha_{2}$ antiplasmin complex (PAP) (Dade Behring) were measured by enzyme linked immunosorbent assay (ELISA) according to the manufacturer's instructions. The lowest sensitivity for the assays were: $\mathrm{D}$-dimer, $100 \mathrm{ng} / \mathrm{ml}$; plasmin- $\alpha_{2}$-antiplasmin complex, $50 \mu \mathrm{g} / \mathrm{l}$; thrombin-antithrombin III complex, $2 \mu \mathrm{g} / \mathrm{l}$. Plasma concentrations of $\mathrm{C}$ reactive protein and the cytokines tumour necrosis factor $\alpha(\mathrm{TNF} \alpha)$, interleukin (IL) 6, and IL8 were measured according to our protocol ${ }^{16}$ by an automated ELISA analyser (Immulite; DPC Europe Limited, Llanberis,
Gwynedd, Wales, UK). The lowest sensitivities for TNF $\alpha$, IL6, and IL8 were $1.7,1.0$, and $2.0 \mathrm{pg} / \mathrm{ml}$ respectively.

Resistance through the oxygenator was calculated at 2 and 12 hours initially and 24 hourly thereafter using the following formula: (pre-oxygenator pressure-post-oxygenator pressure)/ blood flow rate $(\mathrm{mm} \mathrm{Hg} / \mathrm{ml} / \mathrm{min})$.

Heparin and platelet requirements were recorded every 12-24 hours.

\section{Statistical methods}

Data were inspected for normality, and appropriate parametric or non-parametric tests were used. Patient data (gestational age, age at the time of ECMO, birth weight, Apgar score at one and five minutes, $\mathrm{pH}$ before cannulation, oxygenation index, and duration of ECMO) were compared by the Kruskal-Wallis test. Survival rates (defined as survival to discharge from hospital) between the four groups were compared using the $\chi^{2}$ test. Cytokines, TAT, and PAP values were expressed as median (SD). All data were not corrected for dilution. Values of the variables measured before ECMO were compared by the Kruskal-Wallis test, and serial data during ECMO were compared by repeated measures analysis of variance. Data analysed as the change ratio compared with baseline were calculated as follows: (serial data-baseline data)/baseline data. For membrane oxygenator resistance, simple subtraction was used-that is, serial data-data at two hours of ECMO. Significance was assumed when the $\mathrm{p}$ value was less than 0.05

\section{RESULTS}

Table 1 summarises the clinical characteristics of the 20 patients enrolled in this study. There were no significant differences between the four groups in gestational age, birth weight, age at the time of ECMO, Apgar scores at one and five minutes, $\mathrm{pH}$ before cannulation, oxygenation index, duration of ECMO, and survival rate to discharge from hospital. All patients had severe cardiopulmonary failure unresponsive to maximum conventional treatment. The infants were affected by a variety of underlying conditions typical of those seen in our unit during the last nine years. Maximum conventional treatment at referral included nitric oxide, high frequency oscillation, surfactant therapy, and infused prostaglandins.

Table 1 Patient characteristics of the four groups of infants receiving extracorporeal membrane oxygenation (ECMO)

\begin{tabular}{|c|c|c|c|c|c|c|c|c|}
\hline Group & $\begin{array}{l}\text { Gestational age } \\
\text { (weeks) }\end{array}$ & $\begin{array}{l}\text { Birth weight } \\
(\mathrm{kg})\end{array}$ & $\begin{array}{l}\text { Age (hours) at } \\
\text { start of ECMO }\end{array}$ & $\begin{array}{l}\text { pH before } \\
\text { ECMO }\end{array}$ & $\begin{array}{l}\text { Oxygenation } \\
\text { index }\end{array}$ & Mode of ECMO & Hours on ECMO & $\begin{array}{l}\text { Percentage } \\
\text { survival }\end{array}$ \\
\hline $1\left(37^{\circ} \mathrm{C}\right)$ & $39.8(38-41)$ & $3.5(3.1-3.34)$ & $33.4(14-72)$ & $7.4(7.19-7.46)$ & $47(30-69)$ & $\begin{array}{l}\text { 4: VV } \\
\text { 1: VA }\end{array}$ & $172(78-250)$ & 100 \\
\hline $2\left(36^{\circ} \mathrm{C}\right)$ & $40(39-41)$ & $2.95(2.77-3.1)$ & $32.6(13-90)$ & $7.3(7.18-7.43)$ & $49(33-111)$ & $\begin{array}{l}\text { 2:VV } \\
\text { 3:VA }\end{array}$ & 214 (87-373) & 80 \\
\hline $3\left(35^{\circ} \mathrm{C}\right)$ & $36.8(32-40)$ & $3.3(2.8-3.69)$ & $92.2(17-240)$ & $7.3(7.07-7.47)$ & $39(16-53)$ & $\begin{array}{l}\text { 4:VV } \\
1: V A\end{array}$ & 261 (160-369) & 80 \\
\hline $4\left(34^{\circ} \mathrm{C}\right)$ & $39.6(38-40)$ & 3.25 (2.9-3.44) & $146.5(10-648)$ & $7.3(7.14-7.42)$ & $56(20-98)$ & $\begin{array}{l}\text { 4:VV } \\
1: V A\end{array}$ & $214(133-334)$ & 60 \\
\hline
\end{tabular}

Values are mean (range)

VV, Venovenous; VA, venoarterial. 


\begin{tabular}{llll|}
\hline $\begin{array}{l}\text { Table } 2 \\
\text { study }\end{array}$ & Complications recorded during the pilot \\
\hline & Bleeding & $\begin{array}{l}\text { Haemodynamic } \\
\text { problems }\end{array}$ & $\begin{array}{l}\text { Thrombus in } \\
\text { circuit }\end{array}$ \\
\hline Group 1 (Control) & 1 & 0 & 0 \\
Group 2 $\left(36^{\circ} \mathrm{C}\right)$ & 0 & 1 & 1 \\
Group 3 $\left(35^{\circ} \mathrm{C}\right)$ & 1 & 1 & 2 \\
Group 4 $\left(34^{\circ} \mathrm{C}\right)$ & 1 & 0 & 1 \\
\hline
\end{tabular}

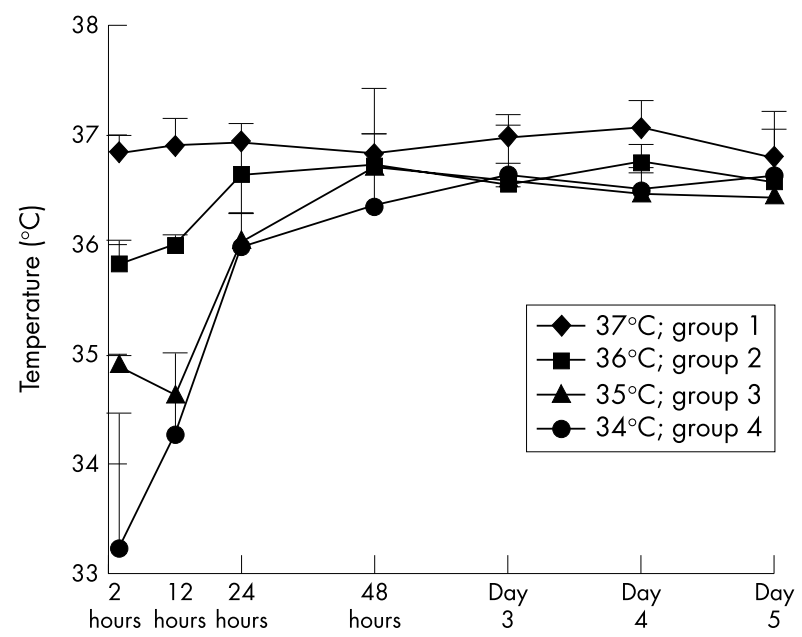

Figure 2 Temperature of each group studied. Values are presented as mean (SD).

Four deaths occurred in the study population, none during the period of hypothermia. These cases are discussed in more detail below. All patients with congenital diaphragmatic hernia were repaired on ECMO after stabilisation. Aprotinin was given continuously before and after the repair to prevent bleeding. No circuit was exchanged during the study period. Venovenous bypass was used in four patients from groups 1, 3, and 4 , and two patients in group 2. Table 2 gives details of ECMO related complications.

\section{Core temperature}

The use of the ECMO heater and radiant warmer to adjust the core temperature of the patients worked well (fig 2). At the end of the period of cooling, the patients were simply rewarmed to $37^{\circ} \mathrm{C}$. Although there was no significant difference in temperature apparent between the groups by 24 hours, clinical restoration of normothermia was not complete until 48 hours in the infants who had been cooled to $34^{\circ} \mathrm{C}$.

\section{Haemodynamics}

In all groups, mean blood pressures were stable throughout the study period, ranging between 30 and $70 \mathrm{~mm} \mathrm{Hg}$. No individual baby had major problems in achieving blood pressure control. Heart rate was also stable, with no episodes of bradycardia - that is, the rate was never noted to fall below 90 beats/min. All patients were able to be weaned off inotropic agents such as adrenaline (epinephrine) and noradrenaline (norepinephrine) after the start of ECMO. No significant differences were observed.

\section{Blood cell counts}

In all groups, platelet count decreased after the initiation of ECMO as a result of haemodilution and consumption in the circuit; this was corrected by transfusion. Similarly haemoglobin levels decreased initially, but were maintained above $120 \mathrm{~g} / \mathrm{l}$ by transfusion after 24 hours. White blood cell counts
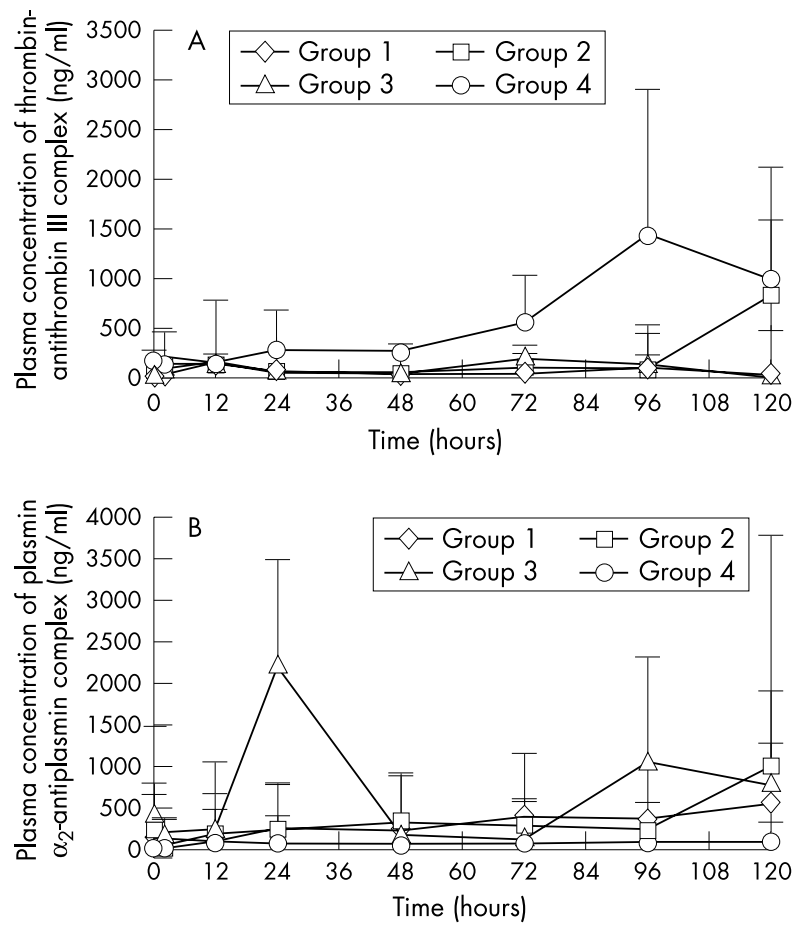

Figure 3 Changes in plasma concentrations of (A) thrombin-antithrombin III complex and (B) plasmin- $\alpha_{2}$-antiplasmin complex are shown for each of the groups. Values are presented as median (SD).

decreased after the start of ECMO and then remained stable throughout the study period. There were no significant differences in any of these variables between the four groups.

\section{Coagulation screening tests}

Prothrombin time and activated partial thromboplastin time increased initially after the start of ECMO in all groups but then decreased and stabilised after 24 hours. Fibrinogen levels showed the same pattern but normalised within 24 hours of administration of cryoprecipitate and fresh frozen plasma. D-Dimer concentrations decreased after the start of ECMO, but subsequently increased throughout the period of study in all groups. One patient in group 3 had an abnormally high prothrombin time and D-dimer levels at baseline, although other coagulation screening tests showed similar results to those of other patients. In all patients, activated clotting time was initially prolonged but was corrected to between 160 and 200 seconds by adjusting heparin dosage according to the policy of the unit. Figure 3 shows changes in levels of thrombin-antithrombin III complex and plasmin- $\alpha_{2}-$ antiplasmin complex. There were no significant differences between the four groups.

Total requirements for platelet transfusion for the initial five days were: $199.6(45.3) \mathrm{ml}$ in group $1 ; 267.8$ (97.3) $\mathrm{ml}$ in group $2 ; 275.7$ (118.9) $\mathrm{ml}$ in group $3 ; 245.5$ (104.1) $\mathrm{ml}$ in group 4. There was no significant difference between the four groups. Total requirements for heparin for the initial five days were: 2625.6 (678.8) units/kg in group 1; 2520.7 (551.5) units/kg in group 2; 2481.9 (1048.7) units/kg in group 3; 3200.9 (1336.0) units/kg in group 4. Again there was no significant difference between the four groups or any trend in the data that might be the result of hypothermia.

No major bleeding complications were observed except at the surgical site of ECMO cannulation, which often occurs because of the initial intravenous administration of heparin and haemodilution caused by the priming of the ECMO circuit. 

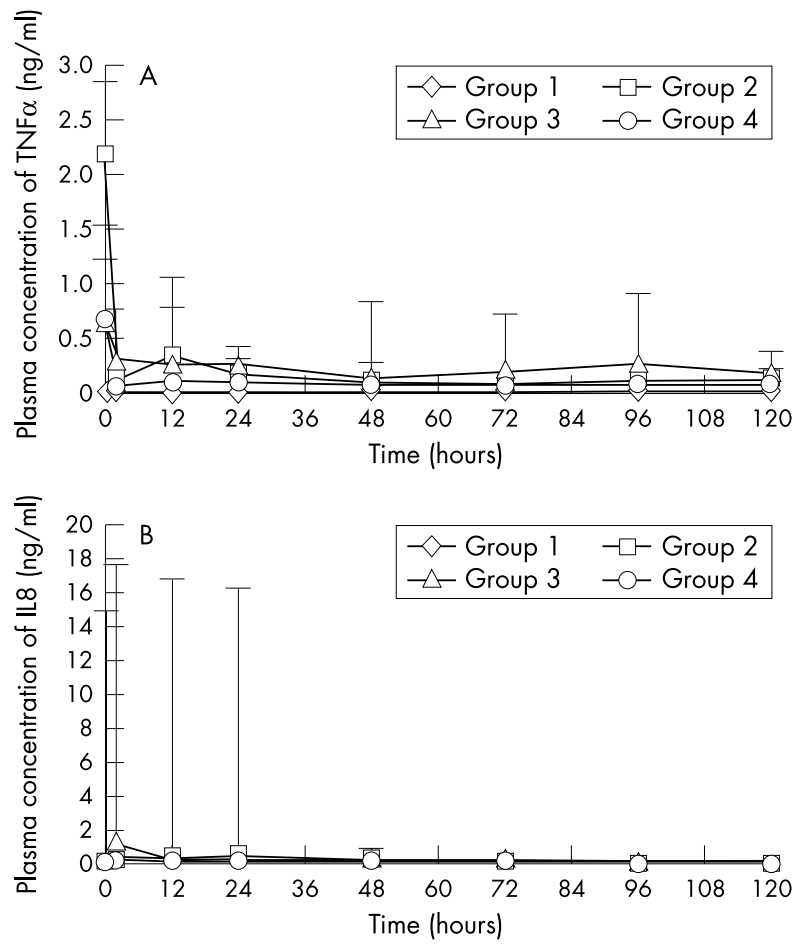

Figure 4 Changes in plasma concentrations of (A) tumour necrosis factor $\alpha$ (TNF $\alpha$ ) and (B) interleukin 8 (IL8) for each of the groups as examples of the observed changes in cytokines. Values are presented as median (SD).

\section{Liver and renal function}

Intravenous administration of frusemide and renal doses of dopamine were used to maintain renal function. For patients unresponsive to pharmaceutical stimulation, continuous venovenous haemofiltration attached directly to the ECMO circuit was used. Blood levels of urea, creatinine, total bilirubin, alkaline phosphatase, alanine aminotransferase, aspartate aminotransferase, and lactate dehydrogenase showed no significant difference between the four groups either before or after the start of ECMO. One of the patients in group 3 had severe liver damage before ECMO was established and this was associated with deranged clotting.

\section{Cytokines}

There were no significant differences in the concentrations of IL6, IL8, and C reactive protein before ECMO between the four groups. However, the concentrations of TNF $\alpha$ in group 2 were significantly $(p=0.0067)$ higher than in the controls (group 1). After ECMO was started, these concentrations fell. Figure 4 shows the levels of IL8 and TNF $\alpha$ as examples of the observed changes.

\section{Calculated membrane oxygenator resistance}

The resistance through the artificial membrane oxygenator increased gradually in all groups over time and there was no significant difference between the four groups. However, the data suggest that the rate at which resistance rose was slower at the lower temperatures. The numbers involved in this investigation are too small for us to be confident about such an effect.

\section{Deaths}

Four infants died before discharge. None of these infants were affected by complications to their ECMO course during the period of hypothermia. The shortest time interval between the period of cooling and death was 17 days. Two of the children who died were referred with diaphragmatic hernias, and a third was found to have surfactant protein B deficiency. The fourth child had no clear initial diagnosis, having presented with severe respiratory distress at term. He eventually died from sepsis at a little over 3 weeks of age during his second ECMO run. This infection appeared to have started during his time off ECMO.

\section{DISCUSSION}

Mild hypothermia has been the focus of much attention in recent years as a means of minimising the cerebral damage that can arise as a result of a hypoxic-ischaemic insult in the perinatal period. ${ }^{9}$ Most of the data are from animal experiments in which the nature and timing of the insult were closely controlled. ${ }^{5-8}$ Translating the technique into clinical practice has posed major problems because, not only is the nature, duration, and severity of perinatal asphyxia not standardised, there is uncertainty about the optimal means of cooling. As cooling is practised in only a limited number of centres and cases of perinatal asphyxia cannot generally be predicted, getting affected infants to the appropriate units for formal testing of the technique is also a problem.

ECMO on the other hand provides life support to a group of infants at high risk of hypoxic-ischaemic brain injury and whose care is already focused on a small number of hospitals. ${ }^{2}$ The technique itself makes control of body temperature very simple, and all infants receiving ECMO are very closely monitored. These babies would therefore appear to be an ideal group in which to assess whether mild hypothermia can provide neuroprotection to human infants. Clearly the situation is not entirely analogous to perinatal asphyxia, as there may be a continuing cerebral insult during ECMO which is assumed not to exist in classical perinatal asphyxia.

There are problems in the use of hypothermia during ECMO. Conventional ECMO is associated with both inflammation and coagulopathy, which seem to be the result of a number of interactions between the blood components and the ECMO circuit materials. ${ }^{16}{ }^{17}$ Probably the most immediate additional concern about the use of hypothermia is that the coagulation system is known to be affected by hypothermia. ${ }^{18} 19$ An in vitro experiment reported that hypothermia at temperatures below $33^{\circ} \mathrm{C}$ produced a coagulopathy that was functionally equivalent to significant $(<50 \%$ of normal activity) factor deficiency states under normothermic conditions, despite the presence of normal clotting factor levels. ${ }^{20}$ Coagulation may also be affected by other factors such as platelet dysfunction or enhanced fibrinolysis. However, these studies were performed in moderate hypothermia (temperature $25-30^{\circ} \mathrm{C}$ ), on short term cardiopulmonary bypass during cardiac surgery. ${ }^{192} 22$ There are, however, no reports of problems related to haemostasis after long term mild hypothermic (temperature about $34^{\circ} \mathrm{C}$ ) extracorporeal perfusion. The lack of significant differences in this study is not surprising given the small size and low power. Our methodology is also open to criticism in that the functional tests, such as prothrombin time, should ideally have been performed at the patient's body temperature. This could not be achieved in a clinical setting. However, we observed no pattern in any of the haematological data or clinical course to suggest a specific effect resulting from the use of mild hypothermia. Nevertheless, this remains an area of concern and merits continued attention because the small numbers and heterogeneity among the patient groups in this study may have prevented a pattern from emerging.

The situation with regard to immune compromise is very similar. Data from patients exposed to more profound hypothermia suggest that immune function is impaired at these low temperatures, ${ }^{19}$ but no data are available in relation to mild hypothermia. In terms of the safety and feasibility of using hypothermia, it is reassuring that, compared with 
infants receiving normothermic ECMO, there was no significant impact on those parts of the immune system that could be measured or on the number and nature of infections observed. However, it is important to remember that the number of infants was small and that the normal values do not, necessarily, equate with normal immune function. Previous studies have indicated that the use of ECMO leads to an inflammatory response, ${ }^{17}$ and it is possible that this would be altered by hypothermia, perhaps in a beneficial fashion. Again there are insufficient data to confirm or refute such a suggestion. The pattern seen in these patients, of falling cytokine levels after the initiation of ECMO rather than the increases described previously, ${ }^{17}$ is typical of our experience of neonates receiving ECMO whether or not they are cooled.

In any observational study, all adverse events must be closely scrutinised. Four babies in this investigation died, giving a survival rate of $80 \%$, which compares favourably with previously reported ECMO series including all patient groups. In three cases (two diaphragmatic hernias, one surfactant protein B deficiency), there was clear evidence that the infants died as a consequence of their presenting complaint. The fourth child was more unusual, with no clear explanation for his initial lung disease. His death with infection, at a little over 3 weeks of age, was almost certainly the result of his sustained period of intensive care rather than the hypothermia at the start of his ECMO run. This experience mirrors that of Gunn et $a l^{23}$ who assessed selective head cooling and mild systemic hypothermia in a group of infants who had sustained perinatal asphyxia. They reported a small number of deaths in both cooled and control infants but without clear evidence of adverse effects as a result of the hypothermia. In a series of infants described by Azzodardi et al, ${ }^{11}$ again deaths were noted but these appeared to be related to their underlying condition and not the hypothermia. These studies are reassuring about the use of mild hypothermia, but formal comparison in a larger group of patients will be necessary to properly assess both safety and efficacy.

This study shows that the use of mild hypothermia for up to 12 hours in patients receiving ECMO is feasible and associated with no adverse effects. Animal experiments suggest that to provide neuroprotection it is necessary to sustain the infants at $34^{\circ} \mathrm{C}$ for $24-48$ hours. It seems reasonable to assess a further group of infants receiving ECMO for this more prolonged period, and, if found to be safe, to move, at that stage, to a randomised trial.

\section{ACKNOWLEDGEMENTS}

This work was funded by the British Heart Foundation.

\section{Authors' affiliations}

S Ichiba, H M Killer, R K Firmin, Heart Link ECMO Centre, Department of Cardiothoracic Surgery, Glenfield Hospital, Leicester, UK

S Kotecha, D Field, Department of Child Health, University of Leicester, UK

A D Edwards, Imperial College Medical School, London, UK

\section{REFERENCES}

1 Stolar CJ, Snedecor SM, Bartlett RH. Extracorporeal membrane oxygenation and neonatal respiratory failure: experience from the Extracorporeal Life Support Organization. J Pediatr Surg $1991 ; 26: 563-71$

2 UK collaborative ECMO trial group. UK collaborative randomised trial of neonatal extracorporeal membrane oxygenation. Lancet 1996;348:75-82.

3 Graziani LJ, Baumgart S, Desai S, et al. Clinical antecedents of neurologic and audiologic abnormalities in survivors of neonatal extracorporeal membrane oxygenation. J Child Neurol 1997; 12:415-22.

4 Hofkosh D, Thompson AE, Nozza RJ, et al. Ten years of extracorporeal membrane oxygenation: neurodevelopmental outcome. Pediatrics 1991:87:549-55.

5 Lorek A, Takei Y, Cady EB, et al. Delayed ("secondary") cerebral energy failure after acute hypoxia-ischemia in the newborn piglet: continuous 48-hour studies by phosphorus magnetic resonance spectroscopy. Pediatr Res 1994;36:699-706.

6 Thoresen M, Bagenholm R, Loberg EM, et al. Posthypoxic cooling of neonatal rats provides protection against brain injury. Arch Dis Child Fetal Neonatal Ed 1996:74:F3-9.

7 Thoresen M, PenriceJ, Lorek A, et al. Mild hypothermia following severe transient hypoxia-ischaemia ameliorates delayed ("secondary") cerebral energy failure in the newborn piglet. Pediatr Res 1995;5:667-70.

8 Edwards, AD, Yue X, Squier MV, et al. Specific inhibition of apoptosis after cerebral hypoxia-ischaemia by moderate post-insult hypothermia. Biochem Biophys Res Commun 1995;217:1 193-9.

9 Mehmet H, Edwards AD, Azzopardi D. Hypoxia, ischaemia, and apoptosis. Arch Dis Child Fetal Neonatal Ed 1996;75:F73-5.

10 Sirimanne ES, Blumberg RM, Bossano D, et al. The effect of prolonged modification of temperature on outcome after hypoxic-ischemic brain injury in the infant rat. Pediatr Res 1996;39:591-7.

11 Azzodardi D, Robertson NJ, Cowan FM, et al. Pilot study of treatment with whole body hypothermia for neonatal encephalopathy. Pediatrics 2000; 106:684-94.

12 The Hypothermia after Cardiac Arrest Study Group. Mild therapeutic hypothermia to improve neurologic outcome after cardiac arrest. N Engl J Med 2002;346:549-56.

13 Clifton GL, Choi SC, Levin HS, et al. Lack of effect of induction of hypothermia after acute brain injury. N Engl J Med 2001;344:556-63.

14 Lazar HL. The treatment of hypothermia. N Engl J Med 1997;337: 1545-7.

15 Firmin RK, Waggoner J, Peason GA. Extracorporeal membrane oxygenation for neonates and older children. In: Lewis T, Graham TR, eds. Mechanical circulatory support. London: Edward Arnold, 1995:78-95.

16 Kotecha S. Cytokines in chronic lung disease of prematurity. Eur J Paediatr 1996;155(suppl 2):514-17.

17 Fortenberry JD, Bhardwaj V, Niemer P, et al. Neutrophil and cytokine activation with neonatal ECMO. J Pediatr 1996;1 28:670-8.

18 Plotz FB, van Oeveren W, Bartlett RH, et al. Blood activation during neonatal extracorporeal life support. J Thorac Cardiovasc Surg 1993; 105:823-32

19 Boldt J, Knothe C, Welters I, et al. Normothermic versus hypothermic cardiopulmonary bypass: Do changes in coagulation differ? Ann Thorac Surg 1996;62:130-5.

20 Johnston TD, Chen Y, Reed L. Functional equivalence of hypothermia to specific clotting factor deficiencies. J Trauma 1994;37:413-17.

21 Lehot JJ, Villard J, Piriz $\mathrm{H}$, et al. Hemodynamic and hormonal responses to hypothermic and normothermic cardiopulmonary bypass. J Cardiothorac Vasc Anesth 1992;6;132-9.

22 Menasche P, Peynet J, Haeffiner-Cavaillon N, et al. Influence of temperature on neutrophil trafficking during clinical cardiopulmonary bypass. Circulation 1995;92(suppl II):334-40

23 Gunn AJ, Gluckmann PD, Gunn TR. Selective head cooling in newborn infants after perinatal asphyxia: a safety study. Pediatrics $1998 ; 102: 885-92$ 